\title{
ОСОБЕННОСТИ ОРГАНИЗАЦИИ ЗАНЯТИЙ ФИЗИЧЕСКОЙ КУЛЬТУРОЙ СТУДЕНТОВ В УСЛОВИЯХ САМОИЗОЛЯЦИИ
}

\section{FEATURES OF ORGANIZATIONS \\ OF STUDENTS ' PHYSICAL CULTURE CLASSES IN CONDITIONS OF SELF-ISOLATION}

V. Lyskov

Summary: The article presents the results of theoretical analysis in the framework of the problem of organizing physical training of students in conditions of self-isolation. The relevance of this study due to the importance of preserving the health of the nation in General and younger generation in particular, that is possible with a systematically organized the implementation of the educational process within the educational subject «Physical culture» and «Elective courses for physical culture and sport» even in the face of the pandemic virus and forced isolation of its subjects. Analysis of the information available to date has allowed us to formulate six main directions, following which, in our opinion, will not only preserve the initial level of physical and psychological performance of students, but also significantly increase the motivation to independently apply the acquired knowledge in the course of implementing the technology health savings and health development, even in remote online mode.

Keywords: physical education, students, pandemic, self-isolation.

\author{
Лысков Владимир Владимирович \\ Преподаватель, Тюменский индустриальный \\ университет, \\ vovan256l@rambler.ru
}

Аннотация: В статье представлены результаты теоретического анализа в рамках проблемы организации занятий физической культурой студентов в условиях самоизоляции. Актуальность настоящего исследования обусловлена значимостью сохранения здоровья нации в целом и подрастающего поколения в частности, что возможно при системно организованной реализации образовательного процесса в рамках учебных дисциплин «Физическая культура» и «Элективные курсы по физической культуре и спорту» даже в условиях вирусной пандемии и вынужденной самоизоляции его субъектов. Анализ имеющейся на сегодняшний день информации позволил сформулировать шесть основных направлений, следование которым, на наш взгляд, позволит не только сохранить первоначальный уровень физической и психологической работоспособности студентов, но и существенно повысить мотивацию к самостоятельному применению приобретенных знаний в ходе реализации технологии здоровье сбережения и здоровье развития даже в условиях дистанционного он-лайн режима.

Ключевые слова: физическая культура, студенты, пандемия, самоизоляция.
$\mathrm{B}$ настоящее время многие образовательные заведения столкнулись с проблемой сохранения эмоционального и физического здоровья учащихся, причиной которой стало распространение коронавирусной инфекции и необходимость соблюдения режима самоизоляции $[4$, c.526]. Ограничение двигательной активности повлекло за собой негативные последствия, среди которых многими учеными были выделены нарушения не только в физическом состоянии учащихся, но и в функциональных нарушениях мозговой деятельности, отразившихся в виде повышения раздражительности, снижение работоспособности, бессонницы и т.д. [1, 3]. В попытки сохранить практику развивающего обучения путем моделирования занятий по дисциплинам «Физическая культура» и «Элективные курсы по физической культуре и спорту» в сложившейся ситуации в условиях реализации требований федерального государственного образовательного стандарта высшего образования мы обратились к использованию инновационных образовательных технологий, реализуемым в учебно-тренировочном процессе по физической культуре.

\section{Теоретическое обоснование проблемы исслеАования}

Опираясь на имеющийся в научной литературе материала, а также на результаты, представленные в исследованиях в контексте темы настоящего [1, 2, 3, 4], нами предложено шесть направлений, учитывающих специфические условия создавшейся ситуации, развитие которых в рамках позволит не только устранить препятствия на пути реализации основных задач физической культуры в пределах осваиваемых студентами дисциплин, но решить более глобальные вопросы, в частности, повышения мотивации учащихся к самостоятельным занятиям физкультурно-оздоровительной деятельности и формирование осознанного отношения к необходимости сохранения своего здоровья средствами физической культуры. Кратко остановимся на каждом из выделенных нами направлений.

Первое направление - активное внедрение современных информационно - коммуникационных технологий (далее - ИКТ), соотносимых с образовательным процессом, реализуемого в стенах ВУЗов. До настоящего 
времени образовательные ИКТ активно использовались преподавателями при организации учебного процесса в ходе дистанционной работы со студентами, однако, в рамках дисциплин «Физическая культура» и «Элективные курсы по физической культуре и спорту», как показала практика выявляется недостаточный уровень как материально-технического обеспечения всех субъектов образовательного процесса, так и методического сопровождения указанной деятельности, осуществляемой в он-лайн режиме. Таким образом, в ходе решения задач в контексте данного направления модернизации необходимо отражение накопленного преподавательским составом профессионального опыта для разработки системных, многоуровневых учебных курсов, позволяющих на постоянной основе транслировать современные знания в области физической культуры и спорту, имеющие под собой научно обоснованный фундамент. Только такое решение способно существенно улучшить качество обучения вне зависимости от возможных влияний со стороны внешних негативных факторов. В контексте сказанного, следует акцентировать внимание на необходимости тщательного продумывания организационной составляющей информационного обмена в системе «педагог - учащийся», позволяющей своевременно корректировать возможные трудности при освоении студентами знаний в рамках образовательных программ.

Второе направление - применение преподавателями технологии критического мышления при разработке и организации учебных занятий в рамках дистанционного обучения по физической культуре. Значимость выделенного направления определяется необходимостью выработки у студентов умения критически относится к различного рода информации, в большом объёме представленной в информационную эпоху. Высокий уровень развития критического мышления позволит учащимся самостоятельно и осознано осуществлять выбор и прогноз различными способами анализа и синтеза получаемой информации, вырабатывая собственное мнение на основе осмысления опыта и идей, используя собственные методики воспитания физических качеств и развития двигательных и координационных способностей.

Tретье направление - использование проектной технологии, позволяющей стимулировать интерес обучающихся к решению конкретных проблем в сфере физической культуры и спорта (врачебно-педагогический контроль, профилактика травматизма и т.д.), предусматривающий освоение студентами определенной суммой знаний в ходе реализации проектной деятельности, на практике применяя полученные знания. Следует отметить существенное преимущество проектной технологии в рамках преодоления препятствий на пути реализации образовательных и воспитательных задач в условиях вирусной пандемии, в частности, в выполнении студентами практических творческих заданий, тре- бующих от них применения освоенных и накопленных знаний для их разрешения. Овладевая культурой проектирования, учащиеся приобретают умение творчески подходить к решению задач в рамках физической культуры и спорта, прогнозировать возможные варианты решения стоящих перед ним задач. В этом случае можно рассчитывать на освоение студентами знаний по применению современных средств и методов неинвазивной скрининг диагностики, которая позволит им самостоятельно осуществлять врачебно-педагогический контроль физической подготовленности и функциональной готовности, а в случае выявления отклонений - применять инновационные устройства, ориентированные на коррекцию выявленных нарушений.

Четвертое направление - применение технологии проблемного обучения, предусматривающей создание под руководством педагога проблемных ситуаций и активную самостоятельную деятельность учащихся по их разрешению. Как результат в этом случае следует рассматривать творческое овладение студентами профессиональными знаниями, навыками, умениями и развитие мыслительных способностей, способные в совокупности значимо положительно отразиться на формировании важных личностных качеств каждого учащегося.

Пятое направление - применение игровые технологий, как вида деятельности, ориентированной на успешное освоение общественного опыта, отражающего основные вопросы совершенствования самоуправления поведением учащихся. Результатом использования игровых технологий следует считать стимулирование учебно-познавательной деятельности учащихся, активизация их мыслительной деятельности, в ходе которой происходит самопроизвольное запоминание сведений, формирование ассоциативного запоминания и рост мотивации к освоению знаний в рамках учебных дисциплин.

Шестое направление - введение здоровье-сберегающих и здоровье-развивающих технологии, способных обеспечить возможность сохранения здоровья в условиях вынужденной самоизоляции в результате формирования у студентов необходимых знаний, умений и навыков, позволяющих их самостоятельно применять при организации здорового образа жизни в повседневной жизни, постоянно увеличивая объём знаний по теории и методики физического воспитания.

\section{Зак^ючение}

Выявленные и названные направления включения современных технологий в образовательный процесс, организуемый в рамках сложившихся условий двигательной ограниченности студентов, способны при 
комплексном решении ситуационной задачи (вирусная пандемия) не только сохранить первоначальный уровень физической и психологической работоспособности студентов, но и существенно повысить мотивацию к самостоятельному применению приобретенных знаний в ходе реализации технологии здоровье сбережения и здоровье развития даже в условиях дистанционного онлайн режима.

\section{ЛИТЕРАТУРА}

1. Базанов, А.Н. Мониторинг здоровья студентов в период вынужденной самоизоляции [Текст] / А.Н. Базанов // Международный журнал гуманитарных и естественных наук. - 2020. - Т.6. - №1 (45) - С.75-78

2. Бамбухова, А.Д. и др. Особенности профессионально-прикладной физической культуры у студентов высших учебных заведений [Текст] / А.Д. Бамбухова, В.А. Шемятихин, И.М. Добрынин // Физическая культура. Спорт. Туризм. Двигательная рекреация - 2018. - С.31-36.

3. Вольчик, В.В. и др. Дистанционное высшее образование в условиях самоизоляции и проблема институциональных ловушек [Текст] / В.В. Вольчик, И.М. Ширяев // Актуальные проблемы экономики и права. - 2020. - Т.14. -№2. - С.235-248.

4. Щадилова, И.С. Организация коммуникативных связей в вузе по дисциплине «Физическая культура» в условиях режима социальной самоизоляции [Текст] / И.С. Щадилова // Ученые записки университета им. П.Ф. Лесгафта. - 2020. - №4 (182). - С.522-527.

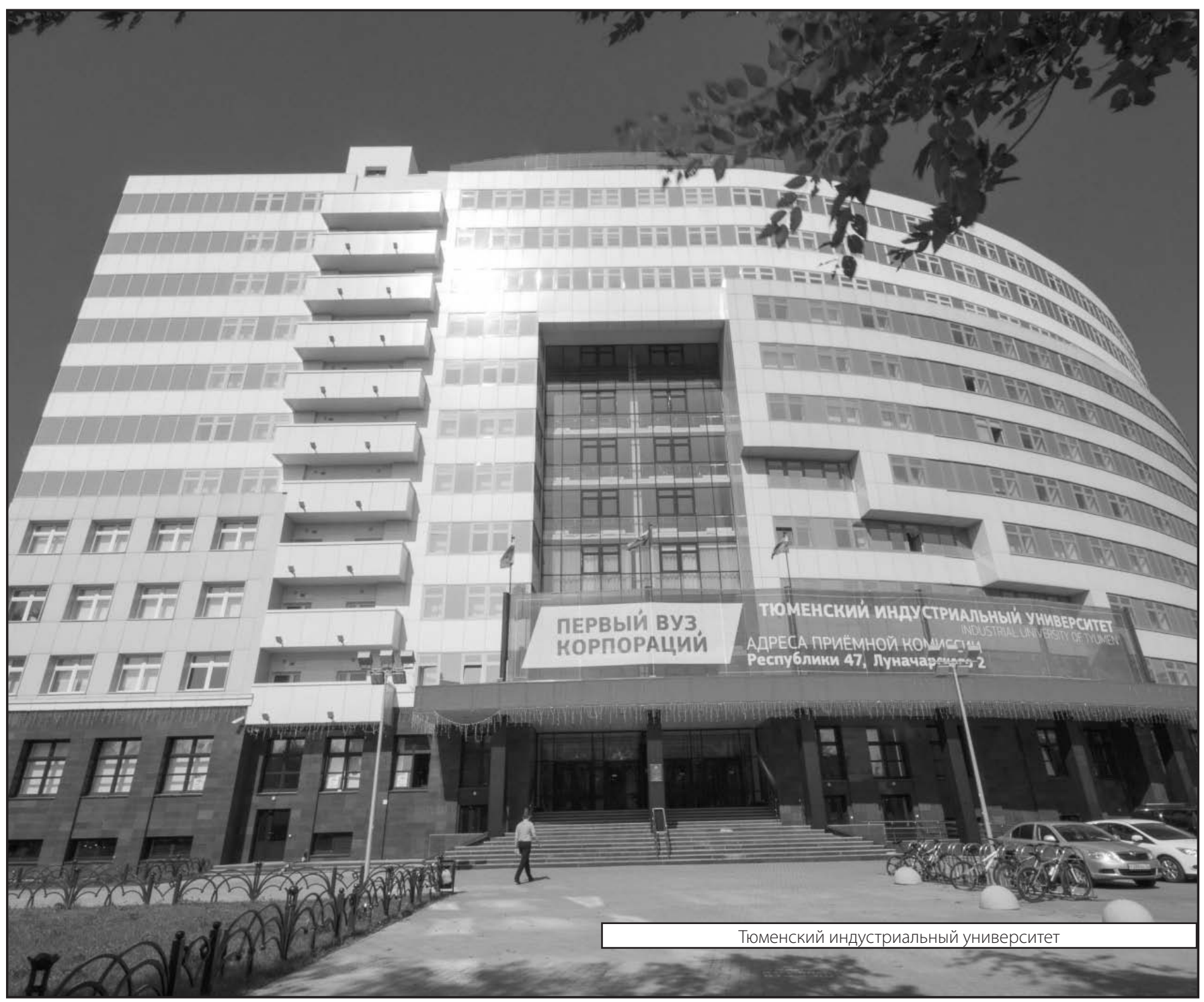

